DOI: https://doi.org/10.47405/mjssh.v5i12.574

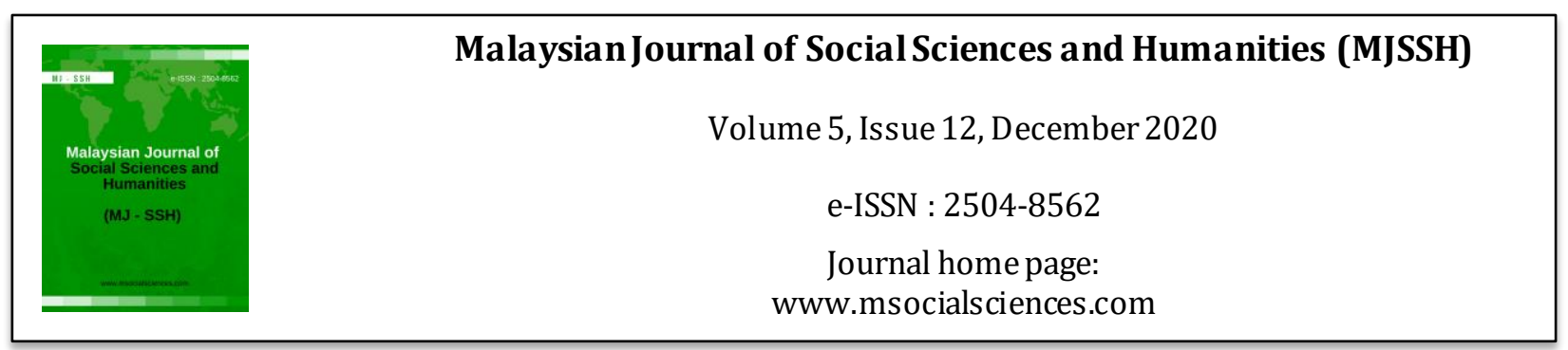

\title{
Keperluan Modul Kejurulatihan Pidato di Sekolah Rendah: Satu Tinjauan Umum
}

Mohd. Farik Madun'1, Musirin Mosin'1

${ }^{1}$ Universiti Malaysia Sabah (UMS)

Correspondence: Mohd. Farik Madun (rikdidik88@gmail.com)

\begin{abstract}
Abstrak
Artikel berbentuk tinjauan umum ini dihasilkan adalah untuk meninjau keperluan modul kejurulatihan pidato di sekolah rendah. Penulisan artikel ini menekankan peri pentingnya kewujudan modul pengajaran kemahiran berhujah seperti pidato dalam bidang pendidikan. Artikel ini juga menunjukkan dapatan literatur berkaitan keperluan membangunkan modul kejurulatihan pidato kepada guru-guru di sekolah meliputi skop di dalam dan di luar negara. Maka, dapatan artikel ini menjustifikasikan bahawa wujud keperluan membangunkan modul kejurulatihan pidato kepada guru Bahasa Melayu di sekolah rendah hasil daripada sorotan literatur yang diperoleh. Artikel ini diharap dapat memberikan sumbangan dalam bidang ilmu dan penerokaan literatur kepada pengkaji yang lain.
\end{abstract}

Kata kunci: pidato, modul, kejurulatihan, sekolah rendah, pendidikan Bahasa Melayu

\section{The Needs of Public Speaking Coaching Module for Primary Schools: A General Review}

\begin{abstract}
This article in the form of a general review was produced to review the needs of public coaching module for primary schools. This article writing emphasizes the importance of argumentation teaching module such as public speaking in the field of education. This article also shows the findings from the local and international literature related to the needs of developing public speaking coaching module to school pupils. Thus, the findings of this article justify that there is a need to develop a public speaking coaching module to Malay Language primary school teachers as a result of literature searched. It is hope that this article will contribute to the field of knowledge and literature exploration to other researchers.
\end{abstract}

Keywords: public speaking, module, coaching, primary schools, Malay language education

\section{Pengenalan}

Kemahiran berhujah seperti aktiviti berpidato merupakan satu daripada cabang seni pengucapan awam ataupun orator. Seni orator amat sinonim dengan keupayan seseorang berkomunikasi ataupun berinteraksi di hadapan khalayak. Kementerian Pendidikan Malaysia (KPM) (2017) meletakkan 
komunikasi sebagai tunjang pertama dalam Kerangka Kurikulum Standard Sekolah Rendah yang menekankan kepentingan penggabungjalinan kemahiran berbahasa baik secara lisan mahupun bukan lisan semasa berinteraksi. Kemahiran bahasa iaitu kemahiran lisan, kemahiran membaca, dan kemahiran menulis merupakan teras kepada Standard Kurikulum Bahasa Melayu. Kemahiran bertutur pula merujuk keupayaan murid berkomunikasi untuk menjalin hubungan dan menyampaikan maklumat, pendapat, perasaan serta idea yang kreatif dan kritis dengan sebutan dan intonasi yang betul secara sopan dan bertatasusila. Penggunaan tatabahasa yang tepat diberikan tumpuan dalam kemahiran bertutur (KPM, 2017). Aktiviti berpidato merupakan satu daripada aktiviti pengajaran dalam kemahiran bertutur Bahasa Melayu. Pidato ialah suatu seni menyampaikan ucapan kepada sekumpulan manusia (Rahmat Ismail, 2000).

\section{Sorotan Literatur}

Sorotan literatur dalam penulisan ini merangkumi dua bahagian iaitu konsep pidato dan rasional pembangunan modul kejurulatihan pidato di sekolah rendah.

\section{Konsep Kemahiran Berpidato}

Pidato ialah suatu seni menyampaikan ucapan kepada sekumpulan manusia (Rahmat, 2000). Menurut Ashby \& Wehmer (2003), pidato ialah aktiviti atau proses menzahirkan idea atau perasaan bagi memberi informasi kepada orang lain. Demikian juga Plato menerusi Teori Dialektik mengatakan bahawa pemidato yang baik ialah seseorang yang mencari apa-apa yang menjadi kepentingan pendengar tetapi bukan kepentingan dirinya (Larson 2004). Merujuk pendapat Nurul Iman et al. (2017), pidato ialah satu cara untuk berkongsi idea dan pendapat secara lisan. Sementara itu, pidato menurut aspirasi KPM ialah kemahiran pengucapan awam yang sewajarnya diasah dalam kalangan murid untuk melahirkan murid yang mampu berhujah dengan berkesan, berfikiran kritis dan berupaya melontarkan pendapat, idea secara logik dan rasional (KPM, 2018). Tuntasnya, kemahiran berpidato dalam konteks penulisan ini bermaksud satu cabang seni pengucapan awam yang dijadikan aktiviti kemahiran bertutur dalam pelaksanaan pembelajaran dan pemudahcaraan (PdPc) subjek Bahasa Melayu di sekolah rendah.

\section{Rasional Pembangunan Modul Kejurulatihan Pidato di Sekolah Rendah}

Pelan Hala Tuju Pendidikan Bahasa Melayu (PHTPBM) 2016-2025 menerusi inisiatif Kerangka Standard Bahasa Melayu bermatlamat untuk melahirkan murid berketerampilan dalam berbahasa Melayu dengan modus operandi pemerkasaan kemahiran lisan dalam PdPc Bahasa Melayu di semua jenis sekolah (KPM, 2017). Hal ini membuktikan betapa peri penting kemahiran lisan diberikan penekanan untuk melahirkan murid yang mahir bertutur dalam bahasa Melayu. Tambahan pula, kesungguhan untuk meningkatkan kemahiran berpidato dalam kalangan murid dapat dilihat menerusi kewujudan Program Interaktif Kemahiran Bahasa Melayu (PIKeBM) yang merupakan hala tuju kesepuluh dalam Pelan Hala Tuju Pendidikan Bahasa Melayu adalah bertujuan untuk memperluas dan meningkatkan kemahiran lisan bahasa Melayu melalui aktiviti kokurikulum. Program ini dapat meningkatkan kemahiran berkomunikasi dan meningkatkan keupayaan bertutur, berhujah, melontarkan idea yang bernas menggunakan bahasa Melayu standard secara berterusan. Antara program yang dilaksanakan termasuklah Program Bicara Pintar (BITARA) Sekolah Rendah melalui aktiviti pidato spontan dan Program BITARA Sekolah Menengah melalui aktiviti Sudut Pidato (KPM, 2017). Bukti kukuh bahawa KPM komited untuk melahirkan murid yang berketerampilan berbahasa Melayu terutama dalam pengucapan awam seperti kemahiran berpidato.

Hasrat KPM yang mewajibkan setiap sekolah untuk menyediakan Sudut Pidato bagi memastikan murid didedahkan dan dilatih dengan kemahiran orator dalam bahasa Melayu adalah amat relevan. Inisiatif ini diharap dapat menghasilkan murid yang mempunyai tahap pengucapan awam yang tinggi dan seterusnya dapat memperkasakan kemahiran berbahasa, mengemukakan pandangan dan pemikiran dalam kalangan murid (KPM, 2018). Sungguhpun begitu, bukan semua guru dapat mengoptimumkan keberadaan Sudut Pidato yang disediakan secara efektif sekiranya pengetahuan dan kemahiran 
berkaitan kejurulatihan pidato masih lagi pada tahap minimum. Hatta, teknik kejurulatihan pidato yang konvensional semata-mata kurang memberikan impak untuk meraih minat murid berpidato. Justeru, kaedah kejurulatihan dan pengajaran kemahiran pidato yang lebih kreatif dan menepati landskap Pendidikan Abad Ke-21 perlu dititikberatkan. Lantaran itu, modul kejurulatihan pidato sewajarnya dibangunkan sebagai panduan kepada guru-guru untuk melatih dan membimbing kemahiran berpidato dalam kalangan murid.

\section{Keperluan Modul Kejurulatihan Pidato di Sekolah Rendah}

Secara umumnya, guru-guru memerlukan modul atau panduan khusus untuk melatih murid berpidato. Hal ini dikatakan demikian kerana kemahiran-kemahiran kejurulatihan yang terkandung di dalam modul pidato dapat dijadikan bahan rujukan yang komprehensif sebagai panduan kepada guru-guru dalam usaha melatih dan mengajarkan seni berpidato kepada murid-murid. Sesungguhnya, kepentingan kemahiran berpidato diajarkan sejak di bangku sekolah rendah lagi tidak perlu dipertikai. Jika ditinjau kurikulum pendidikan bahasa di negara-negara maju, kemahiran berpidato amat ditekankan di peringkat pendidikan primer. Buktinya, Evelin et al. (2018) menyatakan bahawa kemahiran berpidato wajib dikuasai oleh pelajar sekolah rendah di Jerman.

Hal ini amat berbeza dengan kurikulum pendidikan di Malaysia yang kurang menekankan kepentingan pidato sejak dari peringkat sekolah rendah lagi. Di Malaysia, meskipun pelbagai kursus dan bengkel pidato dianjurkan oleh organisasi luar, namun bukan semua ibu bapa berkemampuan untuk menghantar anak-anak mereka bagi mendapatkan bimbingan pidato yang melibatkan kos biayaan. Apatah lagi, kekangan yang dihadapi oleh murid-murid di pedalaman dalam keterbatasan akses Internet dan sumber bahan rujukan. Lantas, kurikulum pendidikan bersepadu dan menyeluruh yang menekankan kepentingan kemahiran berpidato merupakan jawapan yang terbaik agar potensi dan bakat setiap murid dapat digilap sedari kecil. Senada dengan peribahasa Melayu, melentur buluh biarlah daripada rebungnya.

Aktiviti berpidato dapat melatih murid untuk menjanakan idea melalui amalan Kemahiran Berfikir secara Kreatif dan Kritis (KBKK), menyusun idea secara teratur, menggunakan bahasa yang indah dan gramatis serta menganalisis fakta secara rasional dan kritis. Kesemua elemen ini dijelmakan apabila murid menulis teks pidato yang pada akhirnya akan membantu mereka menulis pelbagai jenis karangan seperti karangan jenis pidato, syarahan, ucapan, perbahasan, fakta mahupun perbincangan. Selain itu, keyakinan diri murid dapat dibina. Hal ini berlaku apabila murid dilatih untuk berpidato dengan penuh keyakinan di hadapan khalayak. Pemidato yang baik perlu berpidato secara yakin untuk meyakinkan khalayak. Seandainya pemidato membuat persembahan dengan kurang keyakinan diri, maklumat yang ingin disampaikan tidak akan dapat dicerap dengan baik oleh khalayak. Sesungguhnya, gaya pemidato yang meyakinkan boleh mempengaruhi dalam membujuk pendengar terhadap ucapan.

Hasil penyelidikan Nurul Iman et al. (2017) dalam kajiannya yang bertajuk Meneroka "Speak-ORama" sebagai Modul Pidato: Kajian Kes di Sebuah Sekolah Rendah Integrasi Agama di Malaysia telah membuat perbandingan berkaitan pengajaran kemahiran menulis di sekolah disokong dengan bahan sumber bacaan yang mencukupi. Namun demikian, pengajaran kemahiran lisan menghadapi kekangan apabila aktiviti mendengar murid amat bergantung dengan bimbingan daripada guru-guru bahasa. Hal ini disokong oleh pendapat Setter (2008) yang menyatakan bahawa walaupun kemahiran lisan tidak diabaikan di sekolah, namun lebih penumpuan terhadap kemahiran membaca dan kemahiran menulis menyebabkan perkara ini menjadi tidak seimbang.

Di samping itu, guru-guru juga mengalami kekangan untuk melaksanakan pengajaran kemahiran lisan yang mahu tidak mahu memerlukan bahan sokongan tambahan untuk mencapai objektif PdPc. Perbandingan secara relatif antara ketiga-tiga komponen utama dalam kemahiran bahasa iaitu kemahiran lisan, kemahiran membaca dan kemahiran menulis membuktikan bahawa galakan untuk kemahiran lisan terutama kemahiran bertutur acap kali diabaikan dalam pendidikan (EDK, 2010; Wilson, 1997). Tamsilnya, Maimun (2015) menyimpulkan bahawa majoriti guru masih ketinggalan dalam usaha mengukuhkan kemahiran lisan dalam kalangan murid disebabkan oleh penyepaduan 
kurikulum yang masih lagi dalam peringkat pembangunan. Selain itu, lambakan guru-guru bahasa yang bukan opsyen subjek Bahasa Melayu dan tidak terlatih turut mempengaruhi keadaan ini (Ahmad Zabidi, 2005).

Kemahiran bertutur amat perlu ditekankan bermula di sekolah rendah kerana pada peringkat ini kanakkanak sangat bertindak balas terhadap rangsangan daripada persekitaran (Harris, 2009). Bitterlin et al. (2011) menerangkan bahawa keyakinan diri murid untuk berucap perlu dipupuk menerusi pengalaman sebenar murid dengan penglibatan ahli keluarga, rakan sebaya dan guru-guru. Pembudayaan kemahiran berpidato sepatutnya disemai sejak di sekolah rendah lagi. Murid-murid sekolah rendah selayaknya didedahkan dengan kemahiran berhujah tetapi penerapan kemahiran berpidato pada tahap umur tersebut sering tidak diendahkan dalam mana-mana amalan praktikal dan kajian (Hunt et al., 2014).

Sementara itu, di peringkat sekolah menengah, penggabungjalinan kemahiran berkomunikasi terutamanya kemahiran bertutur dalam pelbagai mata pelajaran kian dititikberatkan. Begitu juga di institusi pengajian tinggi, kemahiran menyampaikan maklumat seperti sesi pembentangan semasa kuliah menjadi keperluan dalam penilaian terhadap penglibatan pelajar secara aktif dalam pelbagai disiplin ilmu. Secara nyata, kedua-dua peringkat persekolahan sama ada sekolah menengah mahupun pengajian tinggi amat menekankan ujian lisan sebagai satu daripada penilaian markah bagi keseluruhan ujian. Hal ini membuktikan bahawa kemahiran berhujah seperti pidato amat diperlukan dalam pelbagai profesion (Common Core State Standards Initiative, 2010; Girard, Pinar, \& Trapp, 2011; Hristova, 2014) dan akhirnya bermanfaat untuk menempuh alam pekerjaan (Morreale, Valenzano, \& Bauer, 2016; Van Ginkel et al., 2015).

Seperkara lagi, kemahiran berpidato bukan hanya memfokuskan tentang seni berbahasa bahkan kemahiran ini merupakan kemahiran yang amat berguna dalam keseluruhan kurikulum sebagai alat pembelajaran dan penilaian ilmu (Lee, Quinn, \& Valdes, 2013). Sebagai contoh, dalam mata pelajaran lain di sekolah seperti Sains mahupun Sejarah, para pelajar hendaklah berupaya untuk menyampaikan pengetahuan dan idea secara pengucapan bermaklumat. Justeru, kebolehan untuk memindahkan ilmu secara lisan akan melatih kemahiran bertutur murid (Min, 2014). Di samping itu, kebolehan untuk menyampaikan maklumat juga relevan apabila pelajar terlibat dalam aktiviti kokurikulum seperti pertandingan forum, pertandingan saintis muda mahupun aktiviti pembentangan semasa perkhemahan unit beruniform. Implikasinya, keupayaan berhujah secara kompeten merupakan keperluan utama untuk pencapaian akademik, kecemerlangan dalam kerjaya profesional seterusnya memenuhi hierarki kepuasan peribadi, (Morreale \& Pearson, 2008).

\section{Kesimpulan}

Konklusinya, pengkaji menyarankan agar modul kejurulatihan pidato dibangunkan sebagai kegunaan guru-guru Bahasa Melayu di semua peringkat persekolahan terutama sekolah rendah. Hal ini bertepatan dengan komentar Pagcaliwagan (2015) yang menegaskan bahawa bahan bantu mengajar seperti modul untuk meneguhkan pengajaran lisan masih lagi sukar ditemukan termasuklah modul kejurulatihan pidato. Keperluan modul sebagai bahan bantu mengajar disokong oleh Richards (2003) yang berpendapat bahawa modul berperanan sebagai panduan untuk pengajaran kemahiran bahasa, set bahan rangsangan untuk menjanakan pemikiran dan idea murid serta sumber rujukan untuk aktiviti berkomunikasi.

Natijahnya, murid-murid akan berasa seronok dengan strategi pengajaran yang berpusatkan bahan melalui penggunaan modul. Secara tidak langsung, motivasi intrinsik murid akan dapat dikukuhkan. Kewujudan modul kejurulatihan pidato ini juga diharap dapat membantu guru untuk menentukan kaedah dan teknik kejurulatihan pidato yang tepat. Tambahan pula, modul seumpama ini akan meningkatkan motivasi guru untuk mengajarkan aktiviti pidato dengan menggunakan kaedah pengajaran yang lebih tepat berbanding kaedah tradisional yang kurang berkesan. Malah, modul ini turut memberikan penekanan terhadap dimensi-dimensi pidato yang perlu diberi keutamaan. 


\section{Rujukan}

Ahmad Zabidi, A. R. (2005). Ciri-ciri sekolah berkesan: implikasinya terhadap pengurusan sekolah agama. Bentong: PTS Professional Publishing.

Ashby M. Peny \& Wehmer S. (2003). Oxford advanced learner's dictionary (6th ed). New York: Oxford University Press.

Bitterlin, G. Johnson, D., Price, D., Ramirez, S., Savage, K.L. (2011). Ventures transition workbook. New York: Cambridge University Press

Common Core State Standards Initiative. (2010). Common core state standards forEnglish language arts \& literacy in history/social studies, science, and technical subjects. Washington D.C.

EDK. (2010). SCHULSPRACHE: Wissenschaftlicher Kurzbericht und Kompetenzmodell: Provisorische Fassung (vor Verabschiedung der Standards). [School language: Scientific short report and model.]. competence Dipetik daripada http://www.edudoc.ch/static/web/arbeiten/harmos/L1_wissB_25_1_10_d.pdf.

Evelin, Jessika, Maike, Ingo, Ulrich. (2018). Putting a speech training program into practice: Its implementation and effects on elementary school children's public speaking skills and levels of speech anxiety. Contemporary Educational Psychology Journal. 55, 176-188.

Girard, T., Pinar, M., \& Trapp, P. (2011). An exploratory study of class presentations and peer evaluations: Do students perceive the benefits? Academy of Educational Leadership Journal, 15(1), 77-94.

Harris, S. (2009). The relationship between self-esteem and academic success among African American students in the Minority Engineering Program at a research extensive university in the southern portion of the United States. Doctoral Dissertation. Louisiana State University.

Hristova, Z. (2014). Using peers to assess oral presentations to foster learning. International Journal of Innovation in Science and Mathematics Education, 22(3), 74-80.

Hunt, S., Wright, A., \& Simonds, C. (2014). Securing the future of communication education: Advancing an advocacy and research agenda for the 21st century. Communication Education, 63(4), 449-461.

Kementerian Pendidikan Malaysia. (2017). Standard Kurikulum Bahasa Melayu Sekolah Rendah. Putrajaya: Bahagian Perancangan dan Penyelidikan Dasar Pendidikan.

Kementerian Pendidikan Malaysia. (2017). Pelan Hala Tuju Pendidikan Bahasa Melayu. Putrajaya: Bahagian Perancangan dan Penyelidikan Dasar Pendidikan.

Kementerian Pendidikan Malaysia. (2018). Dipetik daripada http//www.moe.gov.my/muatturun/pekeliling-dan-garis-panduan/surat-siaran/bahagian-pengurusan-sekolah-harian pada 10 September 2018.

Larson, C.U. (2004). Persuasion: reception and responsibility (10th ed). Belmont: Wadsworth.

Lee, O., Quinn, H., \& Valdes, G. (2013). Science and language for English language learners in relation to next generation science standards and with implications for Common Core State Standards for English language arts and mathematics. Educational Researcher, 42(4), 223-233.

Maimun Aqsha Lubis. (2015). Effective implementation of the integrated Islamic education. Global Journal Al-Thaqafah, 5(1), 59-68.

Min, S. J. (2014). The basic course isn't really all that basic. The Official Journal of the Georgia Communication Association, Inc, 83, 48-52.

Morreale, S. P., \& Pearson, J. C. (2008). Why communication education is important: The centrality of the discipline in the 21st century. Communication Education, 57(2), 224-240.

Morreale, S. P., Valenzano, J. M., \& Bauer, J. A. (2016). Why communication education is important: A third study on the centrality of the discipline's content and pedagogy. Communication Education, 3(41), 1-21.

Nurul Iman, Ariezal, Atirah Izzah, Bazilah Raihan, Noor Hisham, Suhaida, Wan Suzanna A. (2017). Exploring "Speak-O-Rama" as a Public Speaking Module: a pilot study in an Islamic Integrated Primary School: 2200s-3592s. International Journal of Applied Linguistics \& English Literature, 6(2), 249-257. 
Pagcaliwagan, S. (2015). Assessment of instructional materials in speech and oral communication: basis for curriculum enhancement. International Advanced Research Journal in Science, Engineering and Technology, 2(11).

Rahmat Ismail. (2000). Pidato dan berpidato: seni dan teknik. Kuala Lumpur: Utusan Publications and Distributors Sdn Bhd.

Richards J. C. (2003). Developing speaking activities. From theory to practice. Guidelines, (RELC, Singapore), 28(2), 3-9.

Setter, J. (2008). Theories and approaches in English pronunciation. 25 Years of Applied Linguistics in Spain: Milestones and challenges. Murcia: Universidad de Murcia de Publications. 447-457.

Van Ginkel, S., Gulikers, J., Biemans, H., \& Mulder, M. (2015). Towards a set of design principles for developing oral presentation competence: A synthesis of research in higher education. Educational Research Review, 14, 62-80.

Wilson, J. A. (1997). A program to develop the listening and speaking skills of children in a first grade classroom. University of Virginia. 